\title{
Hesy-Ra ...the first dentist
}

In about 2650 BC, a particular title was bestowed on a high Egyptian official... it reads: Wer-ibeh-senjw. Intriguingly, there are alternate translations of the award. Wer implies "Great one". Ibeh may be "dentition" but could also be "ivory". Senjw is a plural form meaning "arrows", or "cutters", or "physicians". So Wer-ibeh-senjw could translate to "Great one of the ivory cutters" or to "Great one of the dentists".

The official is known as Hesy-Ra and his tomb was discovered by Auguste Mariette, a French archaeologist, in 1861, and excavated later by Egyptologist James Quibell. The tomb contained the clues as to which profession the official followed. The walls, 42 metres long, were covered with paintings and objects of daily life... and most relevant were six wooden panels some of which depicted Hesy-Ra in his practice of medicine and dentistry.

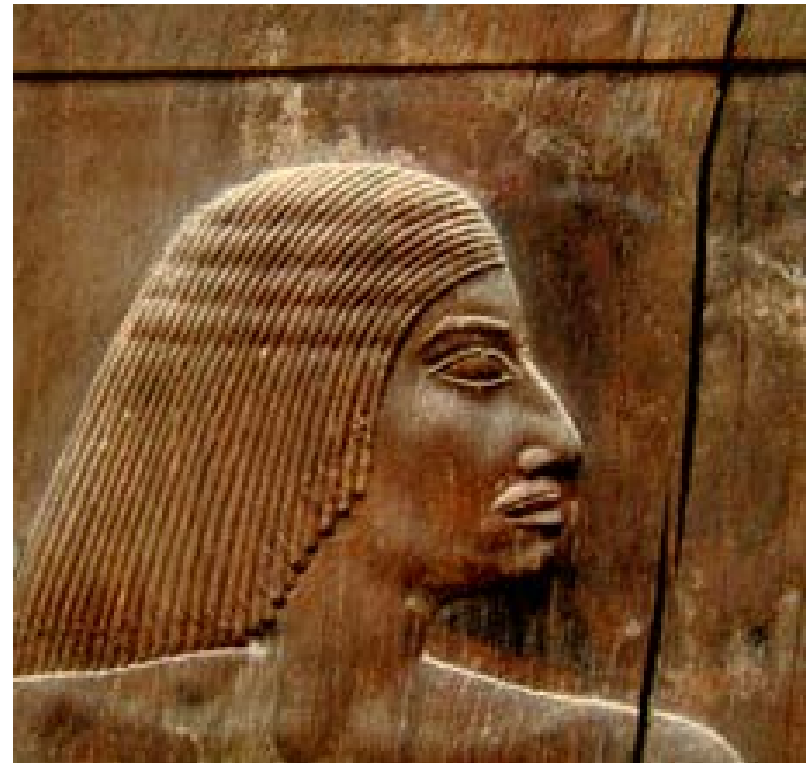

Healthcare was taking root in Egypt at that time, illustrated by collections of texts known as the medical papyri and Hesy-Ra is the first recorded physician and known dentist in history. He evidently was a man of considerable talent for he held several titles, amongst these being:

\section{Confidant of the King: Rekh-neswt}

Great one of the ten of Upper Egypt: Wer-medi-shemaw

\section{Chief of the scribes: Medjeh-seschjw}

\section{Magician of Mehit: Hem-heka-Mehit}

The First Dentist was recognised by society as he was one of the few officials who was permitted to link his name to that of the Sun God, Ra. Those holding that privilege could not use the sun disk hieroglyph as that option was restricted only to the King, Djoser of the Old Kingdom.

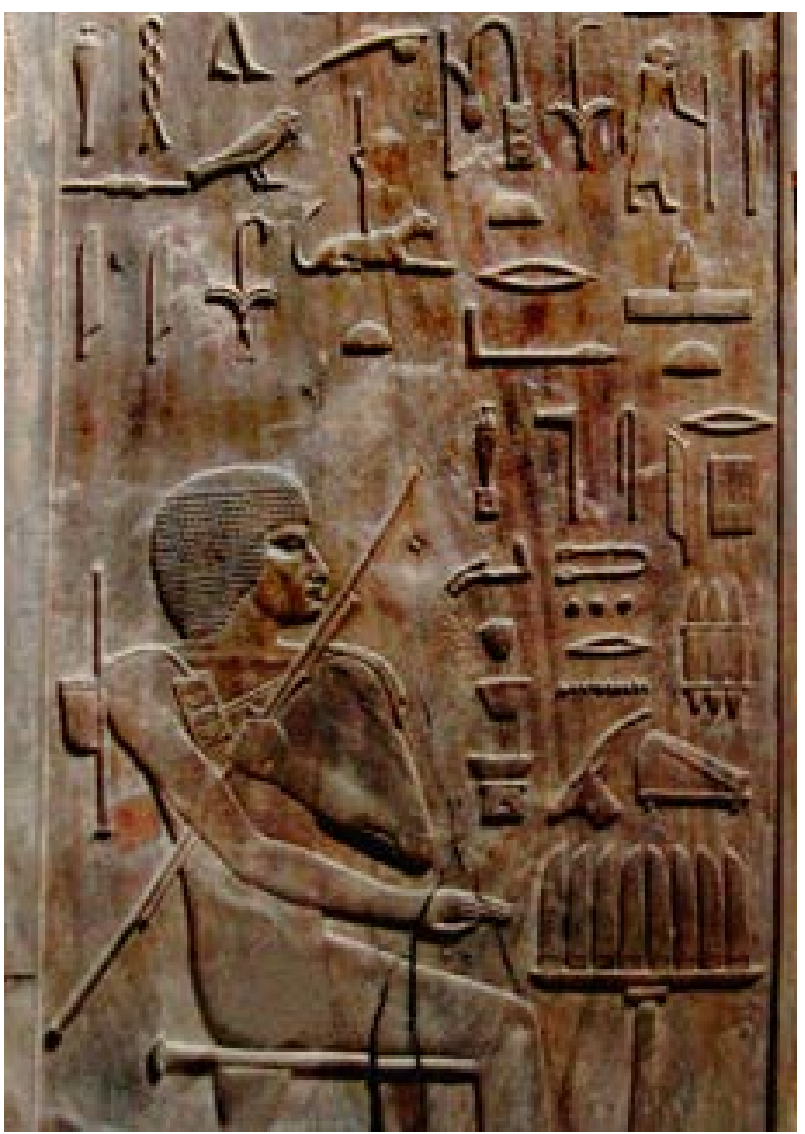

Sections of the wooden panels discovered in the tomb of Hesy-Ra excavated by British archaeologist James Edward Quibel in 1910-1912. Images Sourced: Djehouty, CC BY-SA 4.0

Dentistry can claim that right from the start, ability and commitment and enterprise are characteristics of those in the profession. Dentistry may have taken some four and a half thousand years to reach the expertise of today... the Egyptian Connection provided the firm foundation!

\section{References}

1. https://www.researchgate.net/publication/277553849-Hesyre-The First Recorded Physician and Dental Surgeon in history.

2. https://en. wikipedia.org/w/index.php?title=Hesy-Ra\&oldid= 974922857

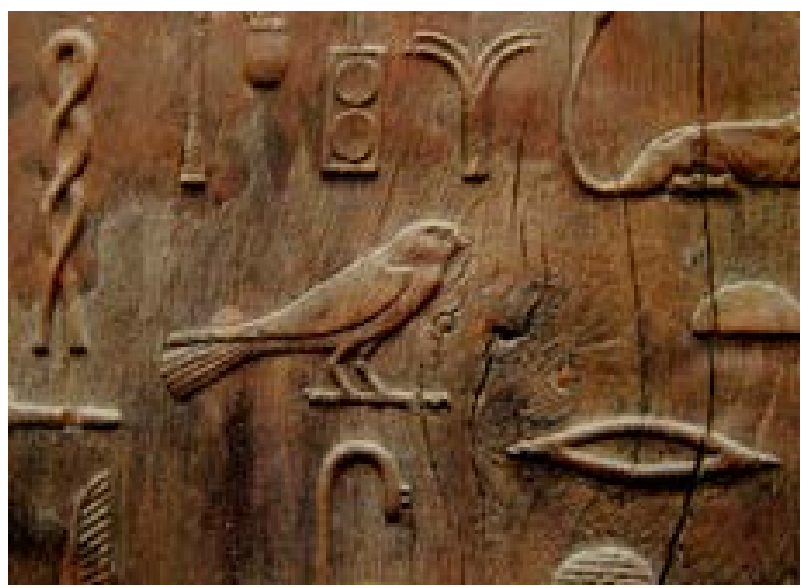

